\title{
A New Method for Evaluating the Visual Quality of Loblolly Pine (Pinus Taeda L.) Forest
}

\author{
Murat Atasoy \\ Faculty of Architecture, Design, and Fine Arts, Osmaniye Korkut Ata University, \\ Osmaniye, Turkey \\ John S. Kush \\ School of Forestry and Wildlife Sciences, Auburn University, Auburn, AL 36849-5418, \\ USA.
}

\begin{abstract}
Most of the forested lands in the south-eastern United States were largely the result of the frequent, low intensity, non-lethal fires that swept through the pre-settlement forests. In the absence of fire, forested stands develop a thick undergrowth of broad-leaved species and herbaceous vegetation. In this study, we compared the influence of prescribed fire on the understory vegetative cover of loblolly pine stands in relation to visual quality assessment. To examine the visual quality of prescribed fire management, a box-counting method was used to analyze photographs of prescribed fire management. The photographs were taken from: a) oneyear fire return interval, b) two-year fire return interval, c) three-year fire return interval, and d) no-burn. The objectives of this study were: 1) develop a comparison of aesthetic value of the different fire return intervals of fire management with areas not experiencing prescribed fire; and 2) provide an estimate of enhancing visual quality of forest stands with prescribed fire management. The results showed that one-year interval prescribed fire application stands had more abundant grass cover (Andropogon sp.) than two-and three-year interval treatments. There was a significant decrease in grass cover between one-year and two-year prescribed burning. A positive relationship was also found between frequency of fire treatment and abundance of grass. No burn areas were covered by woody vegetation which may have a negative impact on scenic beauty and visual quality.
\end{abstract}

KEYWORDS: loblolly pine; prescribed fire; public perception; visual quality assessment

Article Classification: Research paper

\section{Introduction}

Fire was once a common disturbance in numerous ecologically important ecosystems. Recentlydeveloped models suggest that prior to the 1800s large areas of the United States (U.S.) burned multiple times a decade (Guyette et al., 2012). In the southeastern U.S., Virginia to Texas, experienced the most frequent fire return interval (FRI), possibly as short as every $1.5-4.0$ years (Frost 2006, Guyette et al., 2012). An important result of this very short FRIs was to create and maintain an open tree canopy with a diverse herbaceous ground layer (van Lear et al., 2005). Bartram (1791:52), an early traveler through the Southeast, described forested communities this 
way "This plain is mostly a forest of the great long-leaved pine ( $P$. palustris Linn.), the earth covered with grass, interspersed with an infinite variety of herbaceous plants, and embellished with extensive savannahs, always green, sparkling with ponds of water...".

The landscape that Bartram and early settlers encountered was largely the result of the frequent, low intensity, non-lethal fires that swept through the pre-settlement (Mattoon 1922, Chapman 1932). These fires were ignited by a combination of lightning strikes (Komarek, 1974) and aboriginal burning (Robbins and Myers, 1992). The frequent fire had an incredible impact on the flora. Within frequently burned communities, there may be more than 50 plant species existing in a single square meter (Frost 1993, Peet and Allard 1993, Mitchell and Duncan, 2014).

However across much of the modern landscape this natural process of frequent fire has functionally been eliminated. In the absence of fire, forested stands develop a thick undergrowth of broad-leaved species and herbaceous vegetation declines in species diversity due to decreased light and increased litter depth (Peet and Allard, 1993).

The use of prescribed fire (fire that is planned and should be under control) has been prevalent in the Southeast for decades. Prescribed burning is a sustainable and conservative forest management tool needed in the Southeast (Van Lear et al., 2005). Bonnichsen et al. (1987), noted frequent burning is used as a landscape management method to lessen the effects of wildfires, reduce understory fuel accumulation, and create beneficial wildlife habitat. In addition, they reported that annual fire is applied on landscapes to enhance the visual quality and species richness. Costanza and Moody (2011) asserted that long term ecological goals of both public agencies and private conservation organizations include the use of frequent fire.

In order to create a relationship between how people perceive the forest aesthetics of longleaf pine and prescribed fire interval, this study will be used to examine the photos assessed by the people to see if there is a trend related to the number of pixels for the open/grassy understory. Thus, in this study, we compared the influence of prescribed fire on the understory vegetative cover of loblolly pine (Pinus taeda L.) stands in relation to visual quality assessment. Photographs were taken from: a) one-year FRI, b) two-year FRI, c) three-year FRI, and d) no-burn treatment. The objectives of this study were: 1) develop a comparison of aesthetic value of 1-, 2-, and 3-year FRI's with stands not being prescribed burned, and 2) provide an estimate of enhancing visual quality of forest stands with prescribed fire management.

\section{Methods}

\subsection{Study Area}

This study was conducted on the Mary Olive Thomas Demonstration Forest (MOT) consisting of 162 ha tract of land 8 kilometers southeast of Auburn, Alabama. It was bequeathed to the Alabama Cooperative Extension System in 1983 with the stipulation that it be used for the purpose of forest demonstration. Management has been delegated to the School of Forestry and Wildlife Sciences. The overall management objective for MOT is to develop and maintain the property to meet the needs of extension, teaching, and research so as to maximize the benefit to Auburn University and the people of the State of Alabama. The MOT deed and management plan are on-file at the School of Forestry and Wildlife Sciences. The main objective of MOT is to maintain the land to fulfill the requirements of extension, teaching, and research which can be beneficial for public in the area.

In 1996, the MOT management team established a FRI demonstration for landowners with a loblolly pine plantation. Three blocks with 1-2 ha plots within each block were prescribed burned in the dormant season. FRI of 1-, 2-, 3-years and a no-burn were randomly assigned. These treatments continue to this day. 


\subsection{Box-Counting Method}

A box-counting method consists of fractal dimension (FD) which provides a useful determination of shape classifications and graphic analysis including vegetation (Li et al., 2009). The importance of box-counting method and FD has been reported in some studies (Despland and Simpson 2000, Dale et al. 2002, Stamps 2002, Li et al., 2009) which also provided a systematic method for analysis of the indicators of spatial structure of nature such as photographs and microscope images. Thus, in this study, box-counting method was used to identify the relationship between prescribed fire management of loblolly pine understory and visual perception of grass occurrence.

The photographs used in the analysis were taken in January 2016 from four separate locations in the forest to show the differences of understory cover between frequent fire management and no prescribed burning (Figure 1). The box counting method was applied on the photographs taken from different locations of MOT to delineate the pixel numbers of grass scene in each fire treatment plan. Icy-bio image analysis software was used to illustrate the box-counting method and FD within three different photographs of loblolly pine stands (Icy, 2016). The pixel numbers represent the density of grass in the understory of loblolly pine stands. Furthermore, the impact of three different fire intervals were observed by examining the visual differences in pixel densities. Number of pixels was considered as 0 for no-burn treatments since grass did not occur in understory of the no-burn treatment.

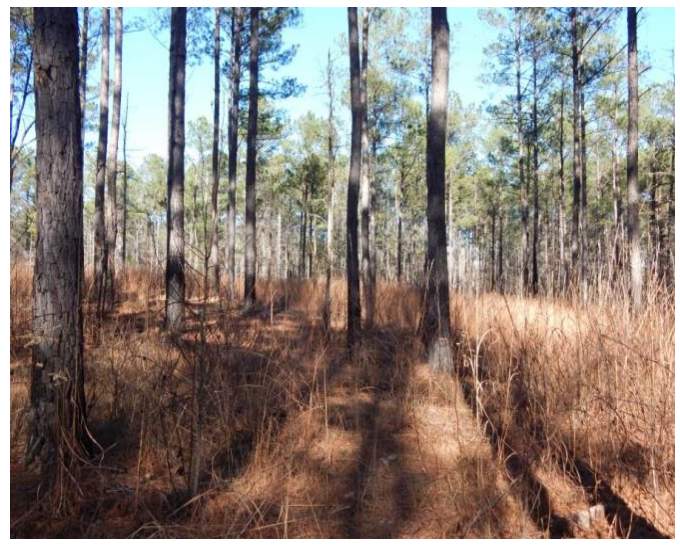

a) One-year fire return interval

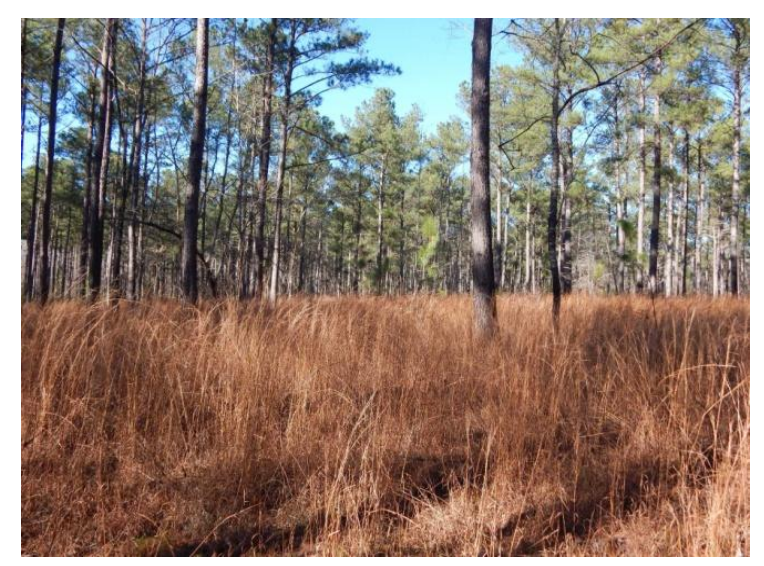

b) Two-years fire return interval 


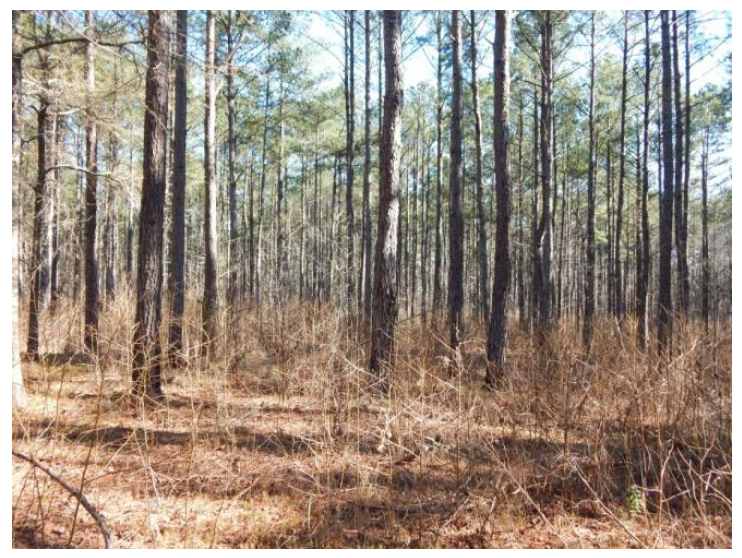

c) Three-years fire return interval

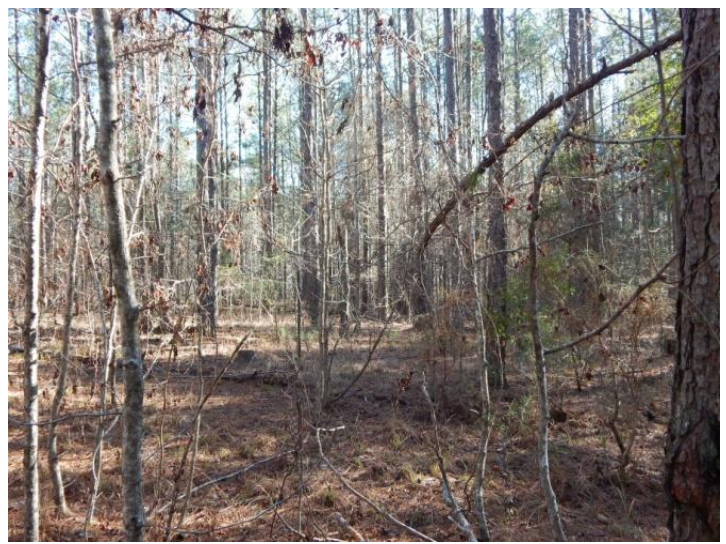

d) Absence of prescribed fire management

Figure 1: Fire return interval groups of prescribed fire management and grass cover in loblolly pine stands on the Mary Olive Thomas Demonstration Forest near Auburn, AL.

\section{Results}

The results of the box-counting analysis showed that there was a significant difference among the prescribed fire treatments for one year interval (Figure 2-a), two years interval (Figure 2-b), three years interval (Figure 2-c) and no burn (Figure 1-a). Pixel number calculation results (Figure 3) showed that the highest rate of grass pixels was 7,439,096 for one year interval, while it was found as $1,974,311$ for two years and 901,885 for three years fire interval. The pixel calculation score was derived as 0 for no burn photographs due to absence of grass. The results of box-counting pixel numbers showed that one-year FRI application stands were more abundant with grass cover than two and three years FRI (Figure 3). Furthermore, the analysis showed that there was a significant decrease in grass cover between one year and two years prescribed burning.

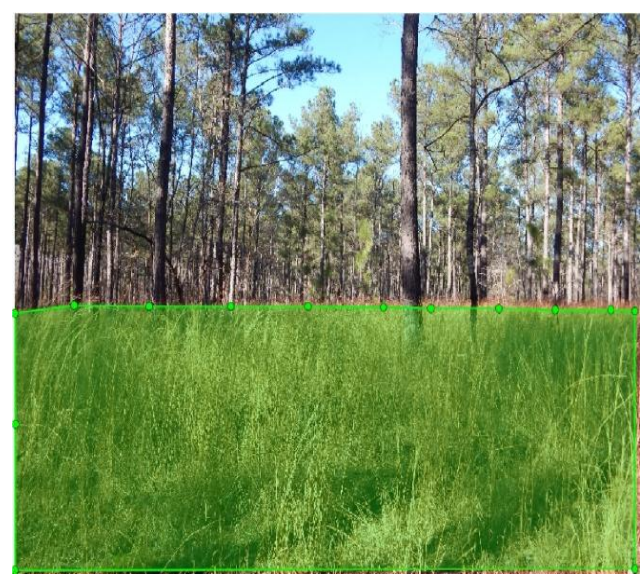

a) One-year fire return interval

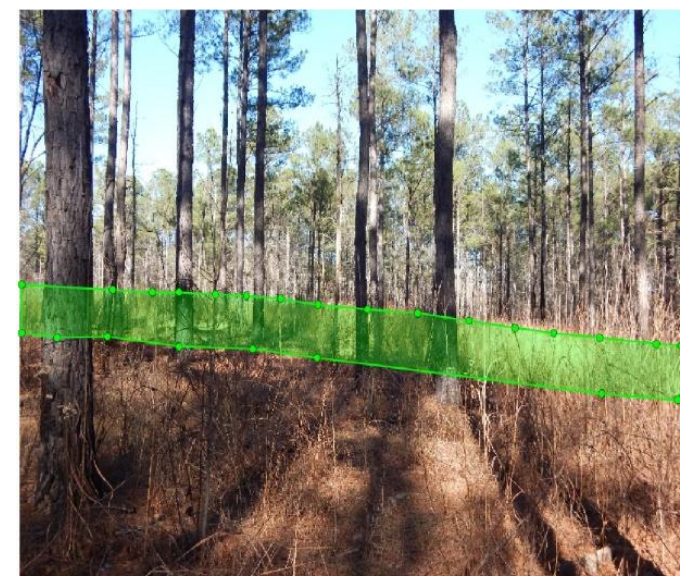

b) Two-years fire return interval 


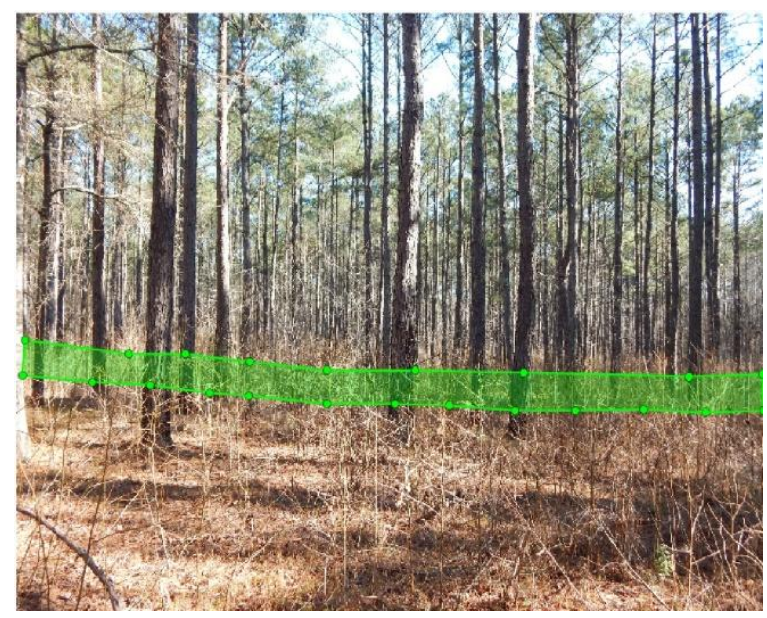

c) Three-years fire return interval

Figure 2: Results of box-counting analysis for fire return interval groups of prescribed fire management and grass cover in loblolly pine stands on the Mary Olive Thomas Demonstration Forest near Auburn, AL.

There was also a positive relationship between frequency of fire treatment and abundance of grass. In addition, no burn areas were covered by woody vegetation which arose a negative impact on scenic beauty and visual quality of the loblolly pine stands. In contrast, photographs taken from one year, two years, and three years interval prescribed fire management stands can be determined as more picturesque and aesthetically efficient. Therefore, grassy vegetative cover may be a significant factor for well-managed loblolly pine and longleaf pine stands in both visual quality and sustainable management systems.

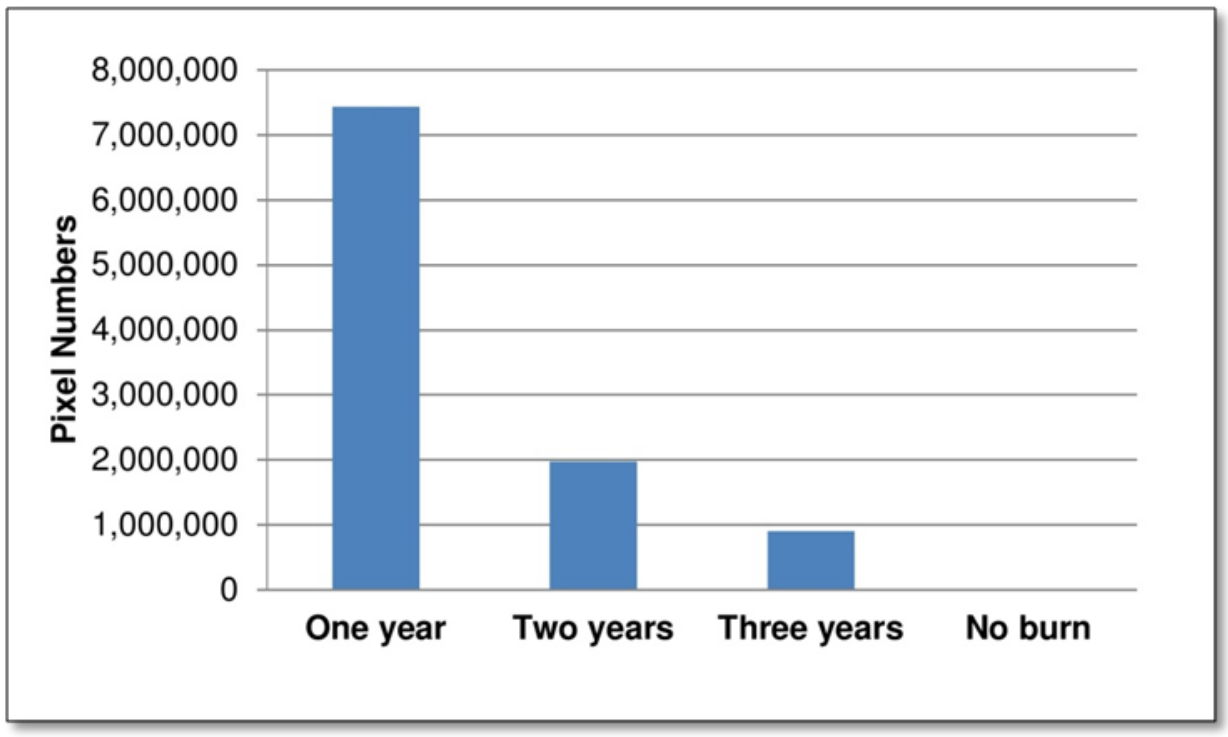

Figure 3: Results of Andropogon sp. understory pixel numbers of loblolly pine forest photographs derived by using box-counting method (one year interval: one year rotation of prescribed fire application, two years interval: two years rotation of prescribed fire application, three years interval: three years rotation of prescribed fire application, and no-burn: absence of fire). 
The results of this study were consistent with Hagerhall and Taylor (2004)'s research which examined 80 different landscape silhouettes to focus on the objective judgment by using standard image processing software. They extracted the landscape silhouette outlines from the images and concluded that there was a significant relationship between preference and FD which can be a section of preference analysis. The results of this study can show that understory vegetation analysis in visual quality assessment can be created by box-counting method and FD. Also, in terms of forest aesthetics, forests with frequent FRI can exhibit more important visual quality than less frequent FRI because of decrease in grass understory. The limitations of this research can be a subjective judgment of photographs, limited number of photographs examined, and some data accuracy in pixel counting. There have been also several other studies applied fractal dimension such as evaluating the texture discrimination (Keller et al., 1989) and observing luminance patterns in natural scenes (Field and Brady, 1997). We therefore suggest that these techniques may be useful for future studies of investigating visual quality assessment of understory vegetation cover by applying box-counting method and FD which may also elucidate spatial data acquisition techniques in the future.

\section{Discussion and Conclusion}

Most of the private landowners in the South are also concerned about the future of their landscape and biodiversity which extrapolates with the restoration of fire-prone species. Fires which were ignited by Native Americans or triggered by nature such as lightning strikes facilitated a suitable habitat for fire tolerant plants, and frequent burning was the nature of these habitats (Barnett, 1999). Understanding how frequent FRI affects the open/grassy understory is significant in terms of sustaining the forest management of fire-maintained ecosystems such as longleaf and loblolly pine forests.

The results of box-counting pixel numbers in this study showed that one-year FRI had more abundant grass cover. Also, pixel calculation results showed that increasing the frequency of FRI's can also increase the cover of grass which consequently enhances the visual quality of open/grassy understory of loblolly pine forests. As these factors are combined with our continuing prescribed fire management and its effects on forest aesthetics of longleaf pine forests research, we hope this will help us better understand how scenic beauty is relevant to observing forest aesthetics in longleaf forests and, if enhanced visual quality has any relationship with understory diversity measures in fire-maintained forests.

The most common point of prescribed fire management related studies was that public opinion surveys on forest management practices. Prescribed fire plays a vital role on public attitude because public has a view of prescribed fire management beyond fire risk management, and in their perception, there might be dramatic changes in forest structure and vista. Also, more information is needed about the influence of prescribed fire management on fire-maintained forests such as longleaf and loblolly pine forests including various treatment seasons and differences between burn applications. Therefore, this study has provided an alternative approach to evaluate the aesthetics and cover of open/understory of loblolly pine forests by using a boxcounting method as a rapid assessment. Hopefully the bias that people have against the application of frequent fire management can be overcome with delineation of before and after fire management on understory of loblolly pine forests.

Additionally, illustrating the differences between no fire and a prescribed fire-managed understory may be well suited as a broad explanatory framework for private landowners and local forest managers to better understand the positive outcomes of frequent fire management. Also, as a social aspect, this study can inform private landowners that scenic beauty of loblolly pine vistas is positively associated with maintaining frequent fire management in an open/grassy understory. For future forest management plans, prescribed management can be understood more clearly if more visual studies are provided to inform what the impacts are for the growth and sustainability of fire-maintained ecosystems. 


\section{References}

[1]. Barnett, J. P. (1999). Longleaf pine ecosystem restoration: the role of fire. Journal of Sustainable Forestry 9(1-2):89-96.

[2]. Bartram, W. (1791). Travels through North and South Carolina, Georgia, East and West Florida. Dover Publications (reprinted 1955), New York.

[3]. Bonnichsen. R., Stanford, D., and Fastook, J. L. (1987). Environmental change and developmental history of human adaptive patterns: the Paleoindian case. The geology of North America and adjacent oceans during the last deglaciation 3:403-424.

[4]. Chapman, H. H. (1932). Is the longleaf type a climax?. Ecology 13(4):328-334.

[5]. Costanza, J. K. and Moody, A. (2011). Deciding where to burn: stakeholder priorities for prescribed burning of a fire-dependent ecosystem. Ecology and Society 16(1):14.

[6]. Dale, M. R., Dixon, P., Fortin, M. J., Legendre, P., Myers, D. E., and Rosenberg, M. S. (2002). Conceptual and mathematical relationships among methods for spatial analysis. Ecography 25(5):558-577.

[7]. Despland, E. and Simpson, S. J. (2000). Small-scale vegetation patterns in the parental environment influence the phase state of hatchlings of the desert locust. Physiological Entomology 25(1):74-81.

[8]. Field, D. J., and Brady, N. (1997). Visual sensitivity, blur and the sources of variability in the amplitude spectra of natural scenes. Vision Research 37(23):3367-3383.

[9]. Frost, C. C. (1993). Four centuries of changing landscape patterns in the longleaf pine ecosystem. Pages 17-43 in Hermann, S.M. (ed.). Proceedings of the 18th Tall Timbers Fire Ecology Conference: The Longleaf Pine Ecosystem: Ecology, Restoration, and Management. Tall Timbers Research Station, Tallahassee, Florida, USA.

[10].Frost, C.C. (2006). History and future of the longleaf pine ecosystem. Pages 9-42 in S. Jose, E. Jokela, and D. Miller, eds. Longleaf Pine Ecosystems: Ecology, Management, and Restoration. New York: Springer-Verlag.

[11].Guyette, R. P., Stambaugh, M. C., Dey, D. C., and Muzika, R. (2012). Predicting Fire Frequency with Chemistry and Climate. Ecosystems 15:322-335.

[12].Hagerhall, C. M., Purcell, T., and Taylor, R. (2004). Fractal dimension of landscape silhouette outlines as a predictor of landscape preference. Journal of Environmental Psychology 24(2): 247255.

[13].Icy. (2016). Retrieved from http://icy.bioimageanalysis.org/.

[14].Keller, J. M., Chen, S., and Crownover, R. M. (1989). Texture Description and Segmentation through fractal geometry. Computer Vision, Graphics, and Image Processing 45:150-166.

[15].Komarek, E. V. (1974). Effects of fire on temperate forests and related ecosystems: Southeastern United States. Pages 251-277 in C. E. Ahlgren and T. T. Kozlowski, eds. Fire and ecosystems. Academic Press, New York.

[16].Li, J., Du, Q., and Sun, C. (2009). An improved box-counting method for image fractal dimension estimation. Pattern Recognition 42(11):2460-2469.

[17].Mattoon, W.R. (1922). Longleaf pine. U.S. Department of Agriculture Bulletin, 1061.

[18].Mitchell, R. J. and Duncan, S. L. (2009). Range of variability in southern coastal plain forests: its historical, contemporary, and future role in sustaining biodiversity. Ecology and Society 14(1): 17.

[19].Peet, R. K. and Allard, D. J. (1993). Longleaf pine vegetation of the southern Atlantic and eastern Gulf Coast regions: a preliminary classification. Pages 45-81 in Hermann, S.M. (ed.). Proceedings of the 18th Tall Timbers Fire Ecology Conference: The Longleaf Pine Ecosystem: Ecology, Restoration, and Management. Tall Timbers Research Station, Tallahassee, Florida, USA.

[20].Robbins, L. E. and Myers, R. L. (1992). Seasonal Effects of Prescribed Burning in Florida: A Review. Miscellaneous Publication No. 8, Tall Timbers Research Station. Tallahassee, FL.

[21]. Van Lear, D.H., Carroll, W.D., Kapeluck, P.R., and Johnson, R. (2005). History and restoration of the longleaf pine-grassland ecosystem: implications for species at risk. Forest Ecology and Management, 211(1), 150-165.

[22].Stamps, A. E. (2002). Fractals, skylines, nature and beauty. Landscape and Urban Planning 60(3): 163-184. 